\title{
Body image amongst elite rugby union players
}

Claire Gibson, Chloe Hindle, Rebecca McLay-Cooke, Joanne Slater, Rachel Brown, Brett Smith, Dane Baker, Philip Healey and Katherine Black

\begin{abstract}
There is limited information on the body image of elite male athletes, however, research suggests there are some athletes who have poor body image and that this may be linked to poor dietary habits. Therefore, the current study investigated body image, and the relationship between body image and age, in elite rugby union players during their pre-season training period.
\end{abstract}

This cross-sectional study was undertaken at the start of the pre-season amongst elite rugby union players in New Zealand. Twenty-six professional rugby union players completed a 49-item questionnaire on body image and disordered eating. A 'body image score' was calculated from questionnaire subscales including 'drive for thinness', 'bulimia' and 'body dissatisfaction', with total scores above twenty indicative of poor body image.

Body image scores varied from 3-41 out of a possible 0-72. Poor body image was indicated in $46 \%$ of the players. Disordered eating behaviours were reported among some participants including binge eating at least once a week $(15 \%, n=4 / 26)$, laxative use $(4 \%, 1 / 26)$. Whereas avoiding certain foods was reported by $77 \%,(20 / 26)$ players. The bulimia sub-scale was inversely associated with age $(P=0.026, \mathrm{r}=$ 0.436 .

At the start of the pre-season training period, many elite rugby union players experience body image concerns. The prevalence of disordered eating behaviours is 
of concern, and needs to be minimised due to the negative impact on health and performance. A focus on younger players may be required in order to reduce disordered eating patterns.

\section{Introduction}

Body image is a multifaceted concept involving both perceptual and subjective aspects, including, how accurately individuals are able to estimate their own body shape and size, and their thoughts and feelings in relation to their perceived body shape (Cafri, 2004). Although body image disorders are seen mainly amongst females (Stanford \& McCabe, 2002) (Ousley, Cordero, \& White, 2008), there are reports suggesting poor body image also occurs in males (DeFeciani, 2016). Furthermore, there are likely to be important differences in the desired body size between males and females. Whereas females desire a smaller size, males are split with some males desiring a smaller size (lower body fat) and others desiring a larger, (more muscular size) (Stanford \& McCabe, 2002). Therefore, on the whole males tend to experience a wider variety of body image issues compared to females.

Despite the limited published research on body image among elite male athletes, the evidence suggests that although many elite male athletes appear to have a positive body image, there are also a number of athletes who are dissatisfied with their body shape (DiGioacchino DeBate, Wethington, \& Sargent, 2002a; Fogelholm \& Hiilloskorpi, 1999; Goltz, Stenzel, \& Schneider, 2013). A study investigating Brazilian male athletes competing in sports which emphasise 'leanness' for performance advantages, aesthetic ideals or weight classes found that $14.7 \%$ had a 
poor body image (Goltz et al., 2013). A Body Shape Questionnaire (BSQ) score above eighty is indicative of body image dissatisfaction (Cooper, Taylor, Cooper, \& Fairburn, 1987). Amongst a different sample of Brazilian male athletes competing in both 'lean’ and 'non-lean’ sports the mean \pm SD BSQ score was $58.9 \pm 26.0$, with scores ranging from 34-164 out of a possible 34-204 (Fortes, Ferreira, de Oliveira, Cyrino, \& Almeida, 2015), suggesting that some male athletes do have poor body image. Although many male athletes desire a leaner body shape, elite ball sport athletes are more likely to desire weight gain and a more muscular body shape (Arroyo, González-de-Suso, Sanchez, Ansotegui, \& Rocandio, 2008; DiGioacchino DeBate et al., 2002a; DiPasquale \& Petrie, 2013; Pamela S. Hinton, Sanford, Davidson, Yakushko, \& Beck, 2004).

Poor body image amongst athletes appears to be associated with behaviours which may affect both performance and health. In elite male university athletes, body image dissatisfaction and drive for muscularity were both associated with negative psychological states and bulimic symptoms (Galli, Petrie, Reel, Greenleaf, \& Carter, 2015) (Petrie, Galli, Greenleaf, Reel, \& Carter, 2013). Others have shown that in a variety of sports elite male athletes with body image dissatisfaction also show signs of disordered eating behaviours (Goltz et al., 2013; Milligan \& Pritchard, 2006). In addition, the risk for disordered eating amongst athletes may be further heightened by common personality traits seen in athletes such as determination, perfectionism and obsession in pursuit of their quest to obtain their desired body composition (Engel et al., 2003; Thompson \& Sherman, 1999). Unfortunately, disordered eating can put the athlete at risk of health issues such as impaired cardiovascular function, kidney disorders, low energy availability, electrolyte disturbance and nutrient deficiencies, as 
well as decreased athletic performance (El Ghoch, Soave, Calugi, \& Dalle Grave, 2013) (Joy, Kussman, \& Nattiv, 2016; Mountjoy et al., 2014).

Eating disorders generally develop during adolescence or during transitional phases in life (Littleton \& Ollendick, 2003). For athletes this could be the transition into the professional sporting environment. It is therefore possible that younger players are more likely to show signs of poor body image and disordered eating compared to their more experienced team-mates, especially during pre-season. For many the pre-season is their first exposure to the professional sporting environment and its associated nutritional support. This may therefore be a time of increased stress amongst these players as they strive to impress coaches and new team-mates. Importantly, it has been shown that amongst adolescents stress is a significant contributor to poor body image (Murray, Byrne, \& Rieger, 2011)

Prior to a rugby union competitive season, a pre-season training period is utilised by athletes to make improvements in strength, conditioning and body composition towards desired ideals for their playing positions (Argus, Gill, Keogh, Hopkins, \& Beaven, 2010; Bradley et al., 2015). Rugby union players can be broadly grouped by their playing positions into endomorphic-mesomorph ‘forwards’ and more balancedmesomorph ‘backs’ (Quarrie et al., 1995). Dietary energy requirements are substantial during the pre-season period due to high exercise energy expenditures plus energy and protein requirements for building lean muscle mass (Bradley et al., 2015) (Thomas, Erdman, \& Burke, 2016). However, negative body image may impact on eating behaviours during this critical time and compromise training adaptations?. 
At present, there are few studies that have investigated the body image of elite male rugby players and further, no study has investigated the relationship between body image and eating behaviour in these athletes. This study aims to investigate the body image and the relationship between body image and age in elite rugby union players during their pre-season training period.

\section{Methods}

\section{Study design and participants}

Using a cross-sectional study design, participants were recruited from one Super

Rugby franchise during the first week of pre-season training (November 2014). All participants provided written informed consent prior to the undertaking the study. Ethical approval for this study was granted by the University of Otago Human Ethics Committee.

\section{Anthropometry}

Body weight was measured using a Tanita BWB-800MA scale, (TANITA, Toykyo, Japan) with the mean body weight calculated from measurements taken on the first morning of three consecutive days of pre-season training. Height measurements were recorded from an online database of the players’ body composition values.

The team dietitian (International Society for the Advancement of Kinanthropometry

Level 1 accredited) measured participants’ skinfolds from eight sites (triceps, subscapular, biceps, iliac crest, supraspinale, abdominal, thigh, medial calf) over the first two days of pre-season training and the sum of eight skinfolds (S8SF) was calculated. Body density was estimated using the sum of four skinfolds (triceps, subscapular, biceps and iliac crest) and regression equations derived by Durnin and 
Womersley (Durnin \& Womersley, 1974). Participants percent body fat was estimated using the Siri equation (Siri, 1956). This was then used to estimate fat-free mass for each player.

\section{Body image and eating behaviour questionnaire}

On the first day of pre-season training (November 2014), participants completed a 49item questionnaire on body image and disordered eating behaviours. The questionnaire was developed from the Low Energy Availability Amongst New Zealand Athletes (LEANZ) questionnaire, (Slater, McLay-Cooke, Brown, \& Black, 2016) which sourced questions from the Low Energy Availability in Female Athletes Questionnaire, and the Eating Disorder Inventory-3 (EDI-3) questionnaire, described elsewhere (Garner, 2004; Melin et al., 2014; Slater et al., 2016). Some questions were further modified to suit the participants in the current study. For example, "have you gained any weight in the past 3 months?” was changed to “do you think you have gained any weight in the off-season?”, and all questions pertaining to menstrual function and oral contraceptive use were removed.

The body image score was calculated from a total of eighteen questions from the EDI3 subscales: drive for thinness, bulimia and body dissatisfaction, previously described elsewhere (Garner, 2004). For each question, responses were made on a six-point Likert-type scale with possible responses: ‘never’, 'rarely’, ‘sometimes’, 'often’, 'usually' or 'always'. Poor body image was defined as a score above twenty, with higher scores indicating greater body image dissatisfaction. Participants were also asked "What is your desired weight?” and "What are your desired skinfolds?" 


\section{Statistical analysis}

Mean and standard deviation (mean \pm SD) values were calculated for the participants' characteristics, body image and subscale scores. All data were checked for normality of distribution using a Shapiro-Wilk test. Differences between forwards and backs were determined using independent t-tests. Differences between questionnaire responses and age were determined using ANOVA. All associations were determined using linear regression. All statistical comparisons were 2-tailed and $p$-values less than 0.05 were considered statistically significant. Statistical analyses were performed using Stata 12 (StataCorp, College Station, TX).

\section{Results}

\section{Participant characteristics}

Participant characteristics are presented in Table 1. A total of twenty-six participants were eligible for the study and completed the body image questionnaire and body composition measures. Broadly divided by their playing positions there were eighteen forwards and eight backs. Participants were all aged over 18 years (range 19 years to 28 years), their body mass ranged from $76.3 \mathrm{~kg}$ to $144.1 \mathrm{~kg}$, and BMI from 25.7 kg. $\mathrm{m}^{2}$ to $42.4 \mathrm{~kg} \cdot \mathrm{m}^{2}$.

\section{Playing position}

The forwards were significantly heavier than the backs $(P<0.001)$ and had higher S8SF ( $P=0.0181$ ) (Table 1). However, there was no significant difference between the forwards and backs for the difference in their actual and desired S8SF, either absolute $(P=0.966)$ or relative $(P=0.502)$. 
There were no significant differences in any of the body image sub-scales or total score (all $P>0.05$ ) between forwards and backs (Table 2).

\section{Body image scores}

Poor body image was indicated for $46 \%(12 / 26)$ of the participants. Mean \pm SD for “drive for thinness”, "bulimia”, "body dissatisfaction” and "total score” are shown in Table 2. The highest scores on the drive for thinness and body dissatisfaction scales were $21 / 24$ and 20/28 respectively, compared to a highest score of $6 / 20$ on the bulimia scale. The highest overall score was 41/72.

\section{Eating behaviour responses}

Sixty-two per cent of participants reported that they never went on eating binges “where they felt they could not stop” while 42\% reported "they had never binged in the previous three months". Binge eating at least once a week was reported by $15 \%$ ( $n=4 / 26)$ of participants. Three of these four players reported "never" or "rarely" feeling out of control during a binge eating episode. However, of the four participants, one reported laxative use 2-6 times a week and another "sometimes" thought about vomiting to try and control body weight and/or skinfold measurements. The regularity of binge eating episodes in the past three months was positively associated with body dissatisfaction $(P=0.017)$.

Over three-quarters (77\%, 20/26) of the participants reported “avoiding certain types of food”. Six participants (23\%) reported that "there are no foods that they avoid”. None of the participants reported following special diets such as vegetarian, vegan or gluten-free. Of the food avoiding participants, 40\% (8/20) reported “avoiding certain foods" as they believed they were "bad for their health”, 30\% (6/20) "avoided foods 
to prevent increases in fat mass and/or skinfolds” and 10\% (2/20) to "avoid gaining weight”. Other reported reasons were “don’t like those types of food” (15\%; 3/20), "want to stay in shape" (5\%; 1/20), "empty calories" (5\%; 1/20), "not part of diet" (5\%; $1 / 20)$, and "foods are high in fat/sugar" (5\%; $1 / 20)$.

Off-season weight gain was reported by $69 \%$ (18/26) of participants, while $31 \%$ (8/26) reported they did not gain weight during the off-season. Of the 18 players that gained weight in the off-season, 12 intentionally gained weight. The main method used to gain weight was gym weights and increasing the amount of food that they were eating, with four of the participants stating that they were consuming protein supplements for this purpose. Of the six players with unintentional weight gain during the off-season four stated they did so because of "lack of training", three stated that "bad diet” was responsible and one participant stated they "had a few beers”.

Eleven participants (42\%) reported previously been told that losing weight would help improve their performance. However, this had no effect on any of their body image scores (“drive for thinness”, “bulimia”, "body dissatisfaction” and "total score”, all $P$ $>0.05)$.

\section{Body composition indices}

There was no significant difference between actual and desired body mass ( $P=0.401)$.

The range for the difference between actual and desired body mass was $-8.33 \mathrm{~kg}$ to $+4.23 \mathrm{~kg}$. There was no significant difference between forwards and backs for the difference between actual and desired body mass.

The mean \pm SD S8SF was $80.5 \pm 29.9 \mathrm{~mm}$ with a range of $49.1 \mathrm{~mm}$ to $157.5 \mathrm{~mm}$.

The desired S8SF mean \pm SD was $70.3 \pm 26.5 \mathrm{~mm}$, ranging from $40.0 \mathrm{~mm}$ to 160.0 $\mathrm{mm}$. This meant there was a mean difference between actual and desired S8SF of -10 
$\mathrm{mm}$ (range $-61.2 \mathrm{~mm}$ to $+95.4 \mathrm{~mm}$ ), with this difference approaching significance $P=0.064$. Five players wanted to increase their S8SF and three players had a desired S8SF that was within $1.0 \mathrm{~mm}$ of their actual S8SF measure.

\section{Age}

There was a significant inverse association between the age of participants and frequency of "stuffing themselves with food" $(P=0.031, \mathrm{r}=-0.558)$ and the frequency of emotional eating $(P=0.011, \mathrm{r}=0.457)$. However, there was no difference seen for the frequency that they thought about binge eating $(P=0.789$, $\mathrm{r}=0.266$ ). There was a significant inverse relationship between the bulimia subscale and age $(P=0.026, \mathrm{r}=-0.436)$.

Younger players also tended to report that they exaggerated the importance of weight/skinfolds more frequently ( $P=0.030, \mathrm{r}=0.433$ ). However, no associations between age and percent difference in actual and desired skinfolds was seen $(P=0.181, \mathrm{r}=0.073)$.

However, there were no age differences in the frequency of losing control whilst eating ( $P=0.341, \mathrm{r}=-0.066)$. Further there were no significant age differences for any question from the body dissatisfaction scale (all $P>0.05$ ).

There were no significant associations between age and body dissatisfaction, drive for thinness, or total score (all $P>0.05$ ). Nor were there any significant associations for the difference between the desired body composition measures and actual body composition measures (all $P>0.05$ ).

\section{Discussion}


The range of body image scores in this study indicates that rugby union players are not homogenous in how they subjectively view their body shape. Considerable variations in body image and desired weight change were seen in the present study, which is in line with previous research in male athletes, including those competing in ball-game sports (Arroyo et al., 2008; Fogelholm \& Hiilloskorpi, 1999). Of concern is the higher prevalence of poor body image in this study (46\%) compared to previously reported $14.7 \%$ in elite male athletes (Goltz et al., 2013). This was not expected as rugby union players tend to have the tall, muscular body shape, considered 'ideal' by society (Banasiak, Wertheim, Koerner, \& Voudouris, 2001; Ridgeway \& Tylka, 2005; Sedeaud et al., 2012). However, elite athletes also experience sports-related pressures to maintain ideal body compositions which can heighten their risk for poor body image and disordered eating behaviours (Krentz \& Warschburger, 2011). Therefore their perception of their body may not reflect that of society.

Previous research has shown a higher body fat percentage in athletes to be associated with greater body image dissatisfaction (Goltz et al., 2013). However, the current study did not observe any associations between the actual body composition measures and responses to body image questions. This is potentially due to the body composition requirements of rugby compared to other sports, which is characterised by lean backs with forwards being heavier with more lean mass and fat mass than the backs (Zemski, Slater, \& Broad, 2015). , In rugby body composition requirements depend on playing positions (Zemski et al., 2015), however, due to the low number of participants available for each playing position it was not possible to determine if associations existed within playing position. 
Conceivably, body image dissatisfaction could affect dietary habits if individuals were motivated to modify their body shape via dietary means, which could influence diet and health. A desired weight loss of $-1.4 \%$ was found in $7 \%$ of elite male university athletes who reported restrictive eating patterns such as chronic dieting and fasting. In comparison, a desired weight change of $+4.6 \%$ was found in the asymptomatic athletes (P. S. Hinton \& Beck, 2005). In male triathletes, of whom $34.9 \%$ desired a smaller body shape and $11.8 \%$ a larger body shape, only $25.5 \%$ meet the six minimum recommended servings of "breads, cereals, rice” food group (DiGioacchino DeBate, Wethington, \& Sargent, 2002b). In the current study 21 participants wanted smaller skinfolds and the difference in their desired weight and actual weight ranged from $-6.4 \%$ to $+4.0 \%$ which exceeds the changes desired by the triathletes who were also showing signs of restrictive eating. However, triathletes have a lower body weight compared to rugby players and triathlon is considered an endurance sport compared to the high intensity high impact nature of rugby therefore their nutritional requirements, and body composition requirements could be substantially different (Duthie, Pyne, \& Hooper, 2003). Although no significant associations were seen between desired and actual weight and bulimia scores, it is possible that those participants who desired a large change in body weight or S8SF were engaging in other practices that were not identified in the current study.

The prevalence of disordered eating behaviours reported in this study is in agreement with previously published values in elite male athletes. Avoiding particular foods is frequent in some athletic populations with $60 \%$ of judokas and $62 \%$ of triathletes reporting food avoidance for weight control (DiGioacchino DeBate et al., 2002b; Rouveix, Bouget, Pannafieux, Champely, \& Filaire, 2007), compared to $77 \%$ in the 
current study. Although not intended for weight control, binge eating is another commonly reported disordered behaviour in elite male athletes. Elite male university athletes reported similar rates of binge eating to the athletes in this present study (17\% vs $15 \%$ in the present study) (P. S. Hinton \& Beck, 2005). However, when divided by sport type, elite university athletes competing in ball sports reported much less binge eating than those competing in other sports (Chatterton \& Petrie, 2013). Nevertheless, not all athletes who reported binge eating also report feeling out of control during a binge, thus the true prevalence of binge eating episodes is likely to be less than that reported. This is consistent with reports in other elite university athletes competing in a variety of sport types (DiPasquale \& Petrie, 2013) (Johnson, Powers, \& Dick, 1999).

Comparatively, the disordered eating behaviours of vomiting, laxative and diuretic abuse are infrequently reported in elite male athletes (Chatterton \& Petrie, 2013; DiPasquale \& Petrie, 2013; Filaire, Rouveix, Pannafieux, \& Ferrand, 2007; Petrie, Greenleaf, Reel, \& Carter, 2008; Thiel, Gottfried, \& Hesse, 1993). Consequences of these behaviours include dental erosion, electrolyte imbalances and dehydration, with the latter two having the potential to directly impair athletic performance (Walsh, Wheat, \& Freund, 2000). Thus, it is still concerning that one athlete in this study reported regular laxative use and another considered vomiting. The inverse associations between these disordered eating patterns and age maybe due to inappropriate nutrition knowledge. Indeed nutrition knowledge has been shown to be a predictor of disordered eating (Neumark-Sztainer, 1996). However, the same pattern was seen with emotional eating and it may be that the times of emotional eating coincide with "stuffing” themselves. This may be reflect a more unsettled home-life. 
Whereas older players are more likely to have a stable home-life and more secure contracts, this may not always be the case for the younger players who may have moved away from home for the first time. Therefore, emotional issues, increased stress and the transitions occurring in their lives both at training and at home, combined with potentially lower nutrition knowledge and cooking skills, could result in poorer nutritional habits. These factors need to be considered when discussing body composition and nutrition with players, in particular, younger players who maybe more susceptible to disordered eating.

\section{Limitations}

The cross-sectional nature of this study means that the long-term impact of these scores cannot be determined, and causal inferences cannot be drawn. The inclusion of performance, injuries and wellness measures throughout the season would have been beneficial. Further it is possible that the disordered eating responses seen by the younger athletes was due to a number of factors including their nutrition knowledge, exposure to a new environment/status within the squad, their living situations and stress. A more detailed questionnaire including these factors would help elucidate these findings, however, the time required to complete a longer questionnaire in this inherently busy population would have significantly reduced participation.

\section{Conclusion:}

It appears that some elite rugby union players do have some body image issues. It is therefore important that support staff are aware that some players, especially younger team members, may be experiencing these issues. These players may require additional support, when providing nutritional and body composition information such as improving nutrition knowledge and addressing stress levels. 


\section{References}

Argus, Christos K., Gill, Nicholas, Keogh, Justin, Hopkins, Will G., \& Beaven, C. Martyn. (2010). Effects of a short-term pre-season training programme on the body composition and anaerobic performance of professional rugby union players. Journal of sports sciences, 28(6), 679-686. doi:10.1080/02640411003645695

Arroyo, Marta, González-de-Suso, José Manuel, Sanchez, Celia, Ansotegui, Laura, \& Rocandio, Ana M. (2008). Body image and body composition: Comparisons of young male elite soccer players and controls. International Journal of Sport Nutrition and Exercise Metabolism, 18(6), 628-638.

Banasiak, Susan J., Wertheim, Eleanor H., Koerner, Jody, \& Voudouris, Nicholas J. (2001). Cultural expectations of muscularity in men: The evolution of playgirl centerfolds. International Journal of Eating Disorders, 29(1), 9093. doi:10.1002/1098-108X(200101)29:1<90::AID-EAT15>3.0.CO;2-F

Bradley, Warren J., Cavanagh, Bryce P., Douglas, William, Donovan, Timothy F., Morton, James P., \& Close, Graeme L. (2015). Quantification of training load, energy intake, and physiological adaptations during a rugby preseason: a case study from an elite European rugby union squad. Journal of Strength and Conditioning Research, 29(2), 534-544.

Cafri, G., \& Thompson, J. K. . (2004). Measuring Male Body Image: A Review of the Current Methodology. . Psychology of Men \& Masculinity, 5(1), 18-29. doi:http://doi.org/10.1037/1524-9220.5.1.18

Chatterton, Justine M., \& Petrie, Trent A. (2013). Prevalence of disordered eating and pathogenic weight control behaviors among male collegiate athletes. Eating disorders, 21(4), 328-341. doi:10.1080/10640266.2013.797822

Cooper, Peter J., Taylor, Melanie J., Cooper, Zafra, \& Fairburn, Christopher G. (1987). The Development and Validation of the Body Shape Questionnaire. International Journal of Eating Disorders, 6(4), 485-494.

DeFeciani, Lisa. (2016). Eating Disorders and Body Image Concerns Among Male Athletes. Clin Soc Work J, 44, 114-123.

DiGioacchino DeBate, R., Wethington, H., \& Sargent, R. (2002a). Body size dissatisfaction among male and female triathletes. Eating and Weight Disorders, 7, 316-323. doi:10.1007/BF03324979

DiGioacchino DeBate, R., Wethington, H., \& Sargent, R. (2002b). Sub-clinical eating disorder characteristics among male and female triathletes. Eating and weight disorders : $E W D, 7(3), 210-220$. Retrieved from http://www.ncbi.nlm.nih.gov/pubmed/12452253

DiPasquale, Laura D., \& Petrie, Trent A. (2013). Prevalence of Disordered Eating: A Comparison of Male and Female Collegiate Athletes and Nonathletes. Journal of Clinical Sport Psychology, 186-197. Retrieved from http://journals.humankinetics.com/jcsp-back-issues/jcsp-volume-7issue-3-september/prevalence-of-disordered-eating-a-comparison-ofmale-and-female-collegiate-athletes-and-nonathletes

Durnin, J. V., \& Womersley, J. (1974). Body fat assessed from total body density and its estimation from skinfold thickness: measurements on 481 men 
and women aged from 16 to 72 years. BrJ Nutr, 32(1), 77-97. Retrieved from http://www.ncbi.nlm.nih.gov/pubmed/4843734

Duthie, G., Pyne, D., \& Hooper, S. (2003). Applied physiology and game analysis of rugby union. Sports Med, 33(13), 973-991. Retrieved from http://www.ncbi.nlm.nih.gov/pubmed/14606925

El Ghoch, Marwan, Soave, Fabio, Calugi, Simona, \& Dalle Grave, Riccardo. (2013). Eating Disorders, Physical Fitness and Sport Performance: A Systematic Review. Nutrients, 5(12), 5140-5160. doi:10.3390/nu5125140

Engel, S. G., Johnson, C., Powers, P. S., Crosby, R. D., Wonderlich, S. A., Wittrock, D. A., \& Mitchell, J. E. (2003). Predictors of disordered eating in a sample of elite Division I college athletes. Eat Behav, 4(4), 333-343. doi:10.1016/S1471-0153(03)00031-X

Filaire, Edith, Rouveix, Matthieu, Pannafieux, Christelle, \& Ferrand, Claude. (2007). Eating Attitudes, Perfectionism and Body-esteem of Elite Male Judoists and Cyclists. Journal of sports science \& medicine, 6(1), 50-57. Retrieved from http://www.pubmedcentral.nih.gov/articlerender.fcgi?artid=3778699\&t ool=pmcentrez\&rendertype $=$ abstract

Fogelholm, M., \& Hiilloskorpi, H. (1999). Weight and diet concerns in Finnish female and male athletes. Medicine and Science in Sports and Exercise, 31(2), 229-235. Retrieved from http://www.ncbi.nlm.nih.gov/pubmed/10063811

Fortes, Leonardo de Sousa, Ferreira, Maria Elisa Caputo, de Oliveira, Saulo Melo Fernandes, Cyrino, Edilson Serpeloni, \& Almeida, Sebasti o Sousa. (2015). A socio-sports model of disordered eating among Brazilian male athletes. Appetite, 92(2015), 29-35. doi:10.1016/j.appet.2015.05.005

Galli, Nick, Petrie, Trent, Reel, Justine J., Greenleaf, Christy, \& Carter, Jennifer E. (2015). Psychosocial predictors of drive for muscularity in male collegiate athletes. Body Image, 14(2015), 62-66. doi:10.1016/j.bodyim.2015.03.009

Garner, David M. (2004). The Eating Disorder Inventory-3: Professional Manual. Odessa, FL: Psychological Assessment Resources Inc.

Goltz, Fernanda Reistenbach, Stenzel, Lucia Marques, \& Schneider, Cláudia Dornelles. (2013). Disordered eating behaviors and body image in male athletes. Revista brasileira de psiquiatria (São Paulo, Brazil : 1999), 35, 237-242. doi:10.1590/1516-4446-2012-0840

Hinton, P. S., \& Beck, N. C. (2005). Nutrient intakes of men and women collegiate athletes with disordered eating. J Sports Sci Med, 4(3), 253-262. Retrieved from http://www.ncbi.nlm.nih.gov/pubmed/24453529

Hinton, Pamela S., Sanford, Tiffany C., Davidson, M. Meghan, Yakushko, Oksana F., \& Beck, Niels C. (2004). Nutrient intakes and dietary behaviors of male and female collegiate athletes. International Journal of Sport Nutrition and Exercise Metabolism, 14(4), 389-405.

Johnson, C., Powers, P. S., \& Dick, R. (1999). Athletes and eating disorders: the National Collegiate Athletic Association study. Int J Eat Disord, 26(2), 179188. Retrieved from http://www.ncbi.nlm.nih.gov/pubmed/10422607

Joy, Elizabeth, Kussman, Andrea, \& Nattiv, Aurelia. (2016). 2016 update on eating disorders in athletes: A comprehensive narrative review with a focus on clinical assessment and management. Journal of Sports Medicine, 50, 154162. doi:10.1136/bjsports-2015-095735 
Krentz, Eva M., \& Warschburger, Petra. (2011). Sports-related correlates of disordered eating in aesthetic sports. Psychology of Sport and Exercise, 12(4), 375-382. doi:10.1016/j.psychsport.2011.03.004

Littleton, H. L., \& Ollendick, T. (2003). Negative body image and disordered eating behavior in children and adolescents: what places youth at risk and how can these problems be prevented? Clin Child Fam Psychol Rev, 6(1), 51-66. Retrieved from http://www.ncbi.nlm.nih.gov/pubmed/12659451

Melin, Anna, Tornberg, Asa B., Skouby, Sven, Faber, Jens, Ritz, Christian, Sjödin, Anders, \& Sundgot-Borgen, Jorunn. (2014). The LEAF questionnaire: a screening tool for the identification of female athletes at risk for the female athlete triad. British Journal of Sports Medicine, 48(7), 540-545. doi:10.1136/bjsports-2013-093240

Milligan, BreeAnn, \& Pritchard, Mary. (2006). The relationship between gender, type of sport, body dissatisfaction, self esteem and disordered eating behaviors in division I athletes. The Online Journal of Sport Psychology, 8(1), 32-46.

Mountjoy, Margo, Sundgot-Borgen, Jorunn, Burke, Louise, Carter, Susan, Constantini, Naama, Lebrun, Constance, ... Ljungqvist, Arne. (2014). The IOC consensus statement: beyond the Female Athlete Triad-Relative Energy Deficiency in Sport (RED-S). British Journal of Sports Medicine, 48(7), 491-497. doi:10.1136/bjsports-2014-093502

Murray, K. M., Byrne, D. G., \& Rieger, E. (2011). Investigating adolescent stress and body image. J Adolesc, 34(2), 269-278. doi:10.1016/j.adolescence.2010.05.004

Neumark-Sztainer, D., Butler, R, \& Palti, H. (1996). Personal and Socioenvironmental Predictors of Disordered Eating among

Adolescent Females. Journal of Nutrition Education, 28, 195-201.

Ousley, L., Cordero, E. D., \& White, S. (2008). Eating disorders and body image of undergraduate men. J Am Coll Health, 56(6), 617-621. doi:10.3200/JACH.56.6.617-622

Petrie, Trent A., Galli, Nick, Greenleaf, Christy, Reel, Justine, \& Carter, Jennifer. (2013). Psychosocial correlates of bulimic symptomatology among male athletes. Psychology of Sport and Exercise, 15(6), 680-687. doi:10.1016/j.psychsport.2013.09.002

Petrie, Trent A., Greenleaf, Christy, Reel, Justine, \& Carter, Jennifer. (2008). Prevalence of eating disorders and disordered eating behaviors among male collegiate athletes. Psychology of Men \& Masculinity, 9(4), 267-277. doi:10.1037/a0013178

Ridgeway, Rebekah T., \& Tylka, Tracy L. (2005). College Men's Perceptions of Ideal Body Composition and Shape. Psychology of Men \& Masculinity, 6(3), 209-220. doi:10.1037/1524-9220.6.3.209

Rouveix, M., Bouget, M., Pannafieux, C., Champely, S., \& Filaire, E. (2007). Eating attitudes, body esteem, perfectionism and anxiety of judo athletes and nonathletes. International Journal of Sports Medicine, 28(4), 340-345. doi:10.1055/s-2006-924334

Sedeaud, Adrien, Marc, Andy, Schipman, Julien, Tafflet, Muriel, Hager, JeanPhilippe, \& Toussaint, Jean-François. (2012). How they won Rugby World Cup through height, mass and collective experience. British Journal of Sports Medicine, 46(8), 580-584. doi:10.1136/bjsports-2011-090506 
Siri, W. (1956). Siri W. University of California Radiation Laboratory Publication No 3349. .

Slater, J., McLay-Cooke, R., Brown, R., \& Black, K. (2016). Female Recreational Exercisers at Risk for Low Energy Availability. Int J Sport Nutr Exerc Metab, 26(5), 421-427. doi:10.1123/ijsnem.2015-0245

Stanford, J. N., \& McCabe, M. P. (2002). Body Image Ideal among Males and Females: Sociocultural Influences and Focus on Different Body Parts. $J$ Health Psychol, 7(6), 675-684. doi:10.1177/1359105302007006871

Thiel, A., Gottfried, H., \& Hesse, F. W. (1993). Subclinical eating disorders in male athletes. A study of the low weight category in rowers and wrestlers. Acta psychiatrica Scandinavica, 88(4), 259-265. Retrieved from http://www.ncbi.nlm.nih.gov/pubmed/8256643

http://onlinelibrary.wiley.com/doi/10.1111/j.16000447.1993.tb03454.x/abstract

Thomas, D. Travis, Erdman, Kelly Anne, \& Burke, Louise M. (2016). Position of the Academy of Nutrition and Dietetics, Dietitians of Canada, and the American College of Sports Medicine: Nutrition and Athletic Performance. Journal of the Academy of Nutrition and Dietetics, 116(3), 501-528. doi:10.1016/j.jand.2015.12.006

Thompson, Ron a, \& Sherman, Roberta Trattner. (1999). “Good Athlete” Traits and Characteristics of Anorexia Nervosa: Are They Similar? (Vol. 7).

Walsh, J. M., Wheat, M. E., \& Freund, K. (2000). Detection, evaluation, and treatment of eating disorders the role of the primary care physician. J Gen Intern Med, 15(8), 577-590. Retrieved from http://www.ncbi.nlm.nih.gov/pubmed/10940151

Zemski, A. J., Slater, G. J., \& Broad, E. M. (2015). Body composition characteristics of elite Australian rugby union athletes according to playing position and ethnicity. J Sports Sci, 33(9), 970-978. doi:10.1080/02640414.2014.977937 